\title{
Fear of coronavirus (COVID-19) and mental health outcomes in Palestine: The mediating role of social support
}

\author{
Fayez Azez Mahamid' (D) . Guido Veronese ${ }^{2} \cdot$ Dana Bdier $^{3}$
}

Accepted: 9 October 2021

(c) The Author(s), under exclusive licence to Springer Science+Business Media, LLC, part of Springer Nature 2021

\begin{abstract}
The current investigation was conducted to test the correlation between fear due to coronavirus (COVID-19) and mental health outcomes (stress, depression, and anxiety) and the mediating role of social support during the Covid-19 Pandemic in Palestine. Structural equation modeling (SEM) was performed to test the conceptual model, where fear of Covid-19 was considered as a predictor, social support as a mediating variable, and mental health (stress, depression, and anxiety) as outcomes. The participants involved were 370 Palestinians, 266 females, and the remaining were males. Participants were recruited through online methods; Facebook advertising, Network email, and Twitter during the COVID-19 in Palestine. Results of the study showed that fear related to COVID-19 was positively and significantly correlated with mental health outcomes (anxiety; $\mathrm{r}=.29, p<.01$, depression; $\mathrm{r}=.25, p<.01$, and stress; $\mathrm{r}=.36, p<.01$ ), while negatively correlated to perceived emotional support $(\mathrm{r}=-.30, p<.01)$, support seeking $(\mathrm{r}=-.29, p<.01)$, and received support $(\mathrm{r}=-.31, p<.01)$. Results of SEM indicated a standardized total effect of social support on mental health outcomes $\left(\beta_{\mathrm{X}, \mathrm{M}}=-.57 ; p<.001\right)$, and an indirect but statistically significant effect (via social support, $\beta_{\mathrm{X}, \mathrm{M}, \mathrm{Y}}=-.286 ; p<.01$ ). These results indicate that social support fully mediated the relationship between fear associated with COVID-19 and mental health distress (stress, depression, and anxiety). The current study supported previous findings demonstrating that fear related to COVID-19 positively correlated with mental health distress (depression, anxiety, and stress). In addition, social support mediated the relationship between fear of COVID19 and mental health outcomes. However, further investigations are needed to test the correlation between current study variables and other associated factors and develop intervention programs targeting affected populations during crises to enhance mental health outcomes.
\end{abstract}

Keywords COVID-19 $\cdot$ Fear of disease $\cdot$ Palestine $\cdot$ Mental health outcomes $\cdot$ Social support

\section{Introduction}

The novel coronavirus disease (COVID-19), according to the World Health Organization (WHO), is an infectious disease in which infected individuals may encounter mild to

Fayez Azez Mahamid

mahamid@najah.edu

Guido Veronese

guido.veronese@unimib.it

Dana Bdier

danamm37@hotmail.com

$1 \quad$ Psychology and Counseling Department, An- Najah National University, Nablus, Palestine

2 University of Milano-Bicocca, Milan, Italy

3 An-Najah National University, Nablus, Palestine moderate respiratory illness. These individuals may recover without requiring hospitalization. However, for older individuals and those with pre-existing conditions, such as diabetes, cardiovascular disease, cancer, and chronic respiratory disease, the risk of developing more severe reactions to the illness, which may result in death, can be higher (Heymann \& Shindo, 2020).

COVID-19 is rapidly spreading across all continents; as of July $20^{\text {th }}, 2021$, global confirmed cases reached 190 . 169. 833, with 4. 086. 000 deaths reported (WHO, 2021a). Arab countries such as Lebanon, Saudi Arabia, Jordan, and Qatar reported growing cases of COVID-19. As of 05:11 pm CEST on July $23^{\mathrm{h}}, 2021,344,717$ infected cases with 3,859 deaths were confirmed in Palestine (WHO, 2021b).

As the new strains of the disease are spreading aggressively, thus allowing for some instances to be fatal, especially among individuals with chronic diseases such as; 
diabetes, cardiovascular, and respiratory diseases (Ai et al., 2020; Cascella et al., 2020). Therefore, like any other disease with similar characteristics, the natural emotional reaction toward this virus would be "fear" and its adverse effects on mental health (Epstein et al., 2008). Fear may best be defined as being in an emotional or motivational state heightened by certain stimuli that may trigger defensive behaviour or escape (Shultz et al., 2016).

Moreover, fear could be triggered by internal or external factors. Internal factors would be characterized by physical symptoms and coping strategies, while external factors would be related to knowledge about the disease, such as online information or the news about the disease (Simard et al., 2013).

Despite fear being considered as a natural emotional reaction that appeared to have a positive effect during the spread of COVID-19, it was characterized by social isolation in order to avoid infection. However, extreme fear may develop into chronic or disproportionate behaviour that becomes harmful, and a core component in the individual developing various psychiatric disorders such as depression, anxiety, and stress in displaying symptoms of post-traumatic stress, and may even lead people to commit suicide (Ornell et al., 2020).

According to the literature, different studies investigated the outcomes that fear had on the mental health of individuals. For example, Mahamid and Bdier (2021a) found that adult Palestinians displayed depression, anxiety, and stress symptoms during the spread of COVID-19. Moreover, a study carried out in Japan found that individuals who experience extreme fear may exhibit different impairments, including adverse effects from unhealthy behaviours (e.g. increased use of alcohol and tobacco, social isolation) as well as disorders impacting mental health (post-traumatic stress disorder, anxiety disorders, depression, somatization) (Shigemura et al., 2020).

Furthermore, Wang et al. (2020) observed that during the spread of COVID-19, Chinese individuals showed moderate to severe levels of anxiety, depression, and stress; however, these levels were lower when they used protection strategies such as masks. Huang et al. (2020) investigated the impact on mental health among clinical front-line medical staff in COVID-19 hotspots and discovered extreme incidences of anxiety and stress disorders among the medical staff.

As people display a fear of becoming infected and choose to stay in quarantine, that is to isolate themselves from others; mental health impairments might be expected to appear among these individuals (Barbisch et al., 2015; Coomes et al., 2020; Huremović, 2019; Lee et al., 2018; Rubin \& Wessely, 2020; Xiang et al., 2020).

In this study, Brooks et al. (2020) expected that individuals in quarantine (isolation) might suffer from depression, stress, anxiety, low mood, insomnia, PTSD, anger, and emotional exhaustion. Instead, an umbrella review revealed that a high level of mental health problems was found among patients, caregivers, and mental health providers (Hossain et al., 2020).

Ivchenko et al. (2020) found that adverse psychological problems during quarantine and isolation among the Italian population included boredom, perceived immobility, and anxiety. On the other hand, Jung and Jun (2020) found that those in quarantine and isolation and suspected of contracting or carrying the virus were linked to depression, posttraumatic stress disorder (PTSD), acute stress disorder, anger, insomnia, irritability, and emotional exhaustion. Therefore, psychological support, psychological interventions, and enhancing social support systems are required in reducing mental health issues among individuals in quarantine and isolation (Zhang et al., 2020; Zhou et al., 2020).

In coping with hardships, social support is identified as one of the leading factors in helping human beings survive (Agbaria et al., 2017; Ronen et al., 2016). Through social support, individuals receive different information; information that causes the individual to believe that others love and care for him or her, and information that causes one to believe that he or she is appreciated and that they belong to a network of human connections and mutual commitment (Agbaria \& Bdier, 2020).

Isolation may lead to reduced access to support from family and friends, degrade social support systems, cause loneliness, and become a risk factor for worsening anxiety and depressive symptoms. As a result, one primary source of social support during the COVID-19 pandemic should come from professionals in the field of psychology (Zhou et al., 2020).

Recent literature highlighted that a lack of social support was a risk factor for depression, anxiety, and PTSD during the outbreak of a viral epidemic (Cabello et al., 2020). For example, for caregivers of children living in HIV-endemic South African communities, social support significantly affected caregiver anxiety (Casale et al., 2014). In addition, lower depression rates among HIV-infected patients were associated with a higher score of social support, especially emotional/informational support and positive social interaction (Matsumoto et al., 2017). Conversely, however, it was found that the degree of anxiety and stress among medical staff treating COVID-19 patients was associated negatively with their levels of social support in January and February 2020 in Wuhan, China (Xiao et al., 2020). Moreover, family and friends social support was found to be a protective factor against mental health distress. Recent studies found that a greater degree of family and friends social support was associated with less depressive symptoms; social support from friends alleviated the effect of anxiety, stress, and depression during the COVID-19 pandemic (Woon et al., 2020; Woon et al., 2021). 


\section{The Current Study}

Our study was carried out in March 2021 and targeted Palestinians in the West Bank of Palestine during the second wave of the Covid-19 pandemic, a setting that is severely affected by poverty, a permanent lack of security, and a lack of sufficient medical services. The negative effect of COVID-19 is severe for populations, such as in the occupied territories of Palestine, who are under unique circumstances. The situation of the occupied territories of Palestine is fraught with environmental stressors (militarization, poverty, lack of employment opportunities, cultural pressures, etc.) and few positive social outlets due to the restrictions on movement between communities, a lack of recreational facilities, and a lack of external support (Mahamid \& Bdier, 2021b).

The current study examines the correlation between fear of COVID-19 and mental health outcomes (anxiety, depression, and stress), and whether social support mediates the correlation between these two variables. Based on previous studies, the following hypotheses were identified: (1) A positive association will be evident between the fear of COVID-19 and mental health distress (anxiety, depression, and stress); (2) mental health problems (anxiety, depression, and stress) will associate negatively with social support; (3) The correlation between fear of COVID-19 and mental health problems (anxiety, depression, and stress) will be mediated by social support.

\section{Methodology}

\section{Participants}

Participants were recruited through online methods; Facebook advertising, Network email, and Twitter during the COVID-19 in Palestine. The aims and procedures of the study were explained online. Participants interested in participation have sent an email to clarify their willingness to participate in the study. Each participant received a letter briefly explaining the subject of the study and its purpose, including ethical issues of confidentiality and voluntary participation. Informed consent was also obtained online from all individual participants included in the study. Participants were 370 Palestinian, involving 266 females and males were remaining. The geographical location of the participants indicated that $46.5 \%$ were from urban population hubs, $45.4 \%$ were from rural villages, and $8.1 \%$ were from internally displaced people's camps. The age representation of participants showed that $45.3 \%$ were between 20-29, 29.6\% were between 30-39, 15.5\% were between $40-49$, and the remaining $9.8 \%$ were between $50-59$. Inclusion in the study required participants to be: 1) Palestinian, 2) native Arabic speakers, and 3) free from having been diagnosed with severe forms of neurodevelopmental mental health impairment. The study was submitted for review and received approval from the An-Najah Institutional Review Board (IRB) before initiating data collection.

\section{Measures}

The research instruments used in this research were translated from English to Arabic and reviewed for content validity and inclusiveness. Ten experts in psychological counseling, Arabic language, and clinical psychology reviewed the research tools; based on the revision committee's feedback, and minor modifications were made. Once completed, the study instruments were back-translated into English by an independent expert in the language., Fifty participants independent from the study sample were asked to answer the scales to test the reliability of the scales (reliability sample); Chronbach's Alpha $\alpha$ indicated high internal consistency for the study instruments. The instruments of the study (Depression, Anxiety and Stress Scale [DASS21], Berlin Social Support Scales [BSSS], and The Fear of Coronavirus-19 Scale [FCV-19S]) were also validated by An-Najah IRB as they were used in previously published studies (Mahamid \& Bdier, 2021a; Mahamid, et al., 2021; Veronese et al., 2021).

Demographic variables: The instruments of our study included the following demographic variables: gender, geographical location, and age.

Depression, Anxiety and Stress Scale (DASS21) The DASS 21 is a 21 item measure designed to test symptoms of depression, anxiety and stress. Individuals are required to mention the presence of symptoms during the previous week to complete the test. Items of scale scored from 3 (most of the time during the last week or very high) to 0 (did not happen to me during the last week). The main goal of DASS is to evaluate the symptoms of anxiety, depression, and anxiety. Consequently, the DASS is not only a measure to assess the symptoms of anxiety, depression, stress among patients; it also allows measuring patient response to the treatment plan. All items of the scale are indicated by letters to which items belong; A (anxiety), D (depression), and S (stress). The total score of each group (Anxiety, Depression, and Stress) should be multiplied by two (Gomez, 2016). In our study, the Cronbach's alpha of DASS 21indicated appropriate internal consistency $(\alpha=0.90)$.

Berlin Social Support Scales (BSSS) The BSSS is a measure designed to test all aspects of social support, including the need for support, perceived social support, support seeking, actually received support, provided supported, and protective social support. The scale was initially designed for use among adults' patients who suffer from cancer and their family members; the scale has been used to measure social 
support among different clinical populations and healthy individuals. Patients rate their responses with each item on a four-point Likert scale; strongly disagree (1), somewhat disagree (2), somewhat agree (3) and strongly agree (4). Negative items of the scale need to be reversed. Patients should complete the first four subscales, and the last two subscales are completed by individuals providing social support to the person. (Schwarzer \& Schulz, 2013). In our study, the first four scales were used. Regarding validity and reliability indicators of BSSS in the Palestinian context, Cronbach's alpha results indicated appropriate internal consistency $(\alpha=0.82)$.

The Fear of Coronavirus-19 Scale (FCV-19S) The FCV-19S is a self-report scale designed to test the fear of the Covid19 Pandemic. The scale including seven items on psychological, behavioural, and emotional reactions related to fear of Covid-19. Patients rate their responses with each item on a five-point Likert scale; 5 (strongly agree), 4 (agree), undecided (3), neither agree nor disagree (2) 1(totally disagree). The scale's total score ranged from 7 to 35 , with a high degree on the scale indicating a high level of fear of COVID-19 (Ahorsu et al., 2020). In our study, the Cronbach's alpha of FCV-19S indicated appropriate internal consistency $(\alpha=0.85)$.

\section{Procedures}

In March 2021, data collection was conducted and focused on Palestinians residing in the West Bank. Samples were recruited online; all participants were informed of the purpose of the research and presented with the instruments' descriptions. Participants who agreed to participate in the research signed a formed consent. The questionnaires were designed to ensure questions would not be of a sensitive or emotionally distressing nature. Furthermore, participants were informed that they were free to withdraw from the study at any time. The research conducted followed guidelines outlined by the An-Najah IRB committee and the Declaration of Helsinki (1964).

\section{Data analysis}

Social support and mental health outcomes among participants, descriptive statistics were calculated to test the level of fear of COVID-19. A Pearson Correlation Coefficient tested the correlation between study variables. To analyze the conceptual model, SEM was performed using IBM SPSS AMOS 25, where fear of Covid-19 was identified as a predictor, social support as a mediator, and mental health distress (Anxiety, depression and stress) as outcomes. The fitness of the model was as follow: $\left(\chi^{2}{ }_{(61)}=241.08 ; p=0.05\right.$, SRMR $<0.07$, RMSEA $<0.08, \mathrm{NFI}>0.95$, NNFI $>0.95$, and CFI $>0.95$ ).

\section{Findings}

Table 1 shows descriptive statistics about the fear of COVID-19, depression, anxiety, stress, and social support. Results indicate that participants received average scores on fear of COVID-19, depression, and actually received support while high scores emerged for, perceived emotional support, support seeking, and stress. Low scores were scored on the anxiety scale. Regarding reliability, all measures showed a high level of reliability values ranging from 0.81 (fear of COVID-19 and support seeking) to 0.93 (depression).

Correlational analysis results in Table 2 indicated that fear of COVID-19 positively correlated with mental health indicators (anxiety; $\mathrm{r}=0.29, p<0.01$, depression; $\mathrm{r}=0.25$, $p<0.01$, and stress; $\mathrm{r}=0.36, p<0.01$ ), while negatively correlated to perceived emotional support $(\mathrm{r}=-0.30, p<0.01)$, support seeking $(\mathrm{r}=-0.29, p<0.01)$, and actually received support $(\mathrm{r}=-0.31, p<0.01)$. Moreover, perceived emotional support positively correlated to support seeking $(\mathrm{r}=0.44$, $p<0.01)$, and actually received support $(\mathrm{r}=0.45, p<0.05)$, while negatively correlated to anxiety $(\mathrm{r}=-0.21, p<0.01)$, depression $(\mathrm{r}=-0.27, p<0.01)$, and stress $(\mathrm{r}=-0.18$, $p<0.01)$. Support seeking negatively correlated to anxiety $(\mathrm{r}=-0.18, p<0.01)$, depression $(\mathrm{r}=-0.23, p<0.01)$, and stress $(\mathrm{r}=-0.26, p<0.01)$. Actually received support
Table 1 Descriptive statistics for research variables $(N=370)$

\begin{tabular}{lcccccccc}
\hline Variable & Mean & S.D & Min & Max & Range & Skewness & Kurtosis & Reliability \\
\hline Fear of Covid-19 & 2.290 & .333 & 1.71 & 3.86 & 2.14 & 1.774 & 10.667 & .87 \\
Perceived Emotional Support & 3.533 & .421 & 2.50 & 4.00 & 1.50 & -.467 & -.919 & .83 \\
Support Seeking & 3.276 & .432 & 2.20 & 4.00 & 1.80 & .053 & -.667 & .80 \\
Actually received support & 2.848 & .269 & 2.00 & 3.50 & 1.50 & -.162 & 4.079 & .81 \\
Anxiety & 1.036 & 1.116 & .00 & 5.43 & 5.43 & 1.165 & 6.245 & .90 \\
Depression & 1.450 & 1.182 & .00 & 6.00 & 6.00 & 1.211 & 4.424 & .93 \\
Stress & 2.040 & 1.277 & .00 & 6.00 & 6.00 & .547 & 10.667 & .91 \\
\hline
\end{tabular}


Table 2 Correlations among study variables $(N=370)$

\begin{tabular}{llllllll}
\hline Measures & $(1)$ & $(2)$ & $(3)$ & $(4)$ & $(5)$ & $(6)$ & $(7)$ \\
\hline (1)Fear of Covid-19 & 1 & $-.30^{* *}$ & $-.29^{* *}$ & $-.31^{* *}$ & $.29^{* *}$ & $.25^{* *}$ & $.36^{* *}$ \\
(2)Perceived Emotional Support & & 1 & $.44^{* *}$ & $.45^{* *}$ & $-.21^{* *}$ & $-.27^{* *}$ & $-.18^{* *}$ \\
(3)Support Seeking & & & 1 & $.59^{* *}$ & $-.18^{* *}$ & $-.23^{* *}$ & $-.26^{* *}$ \\
(4)Actually received support & & & & 1 & $-.27^{* *}$ & $-.20^{* *}$ & $-.21^{* *}$ \\
(5)Anxiety & & & & 1 & $.67^{* *}$ & $.74^{* *}$ \\
(6)Depression & & & & & 1 & $.75^{* *}$ \\
(7) Stress & & & & & 1 \\
\hline
\end{tabular}

${ }^{*} p<0.05, * * p<0.01$
Fig. 1 Conceptualized effect for the fear of Coronavirus (COVID-19) on depression, anxiety and stress, and the mediator role of social support

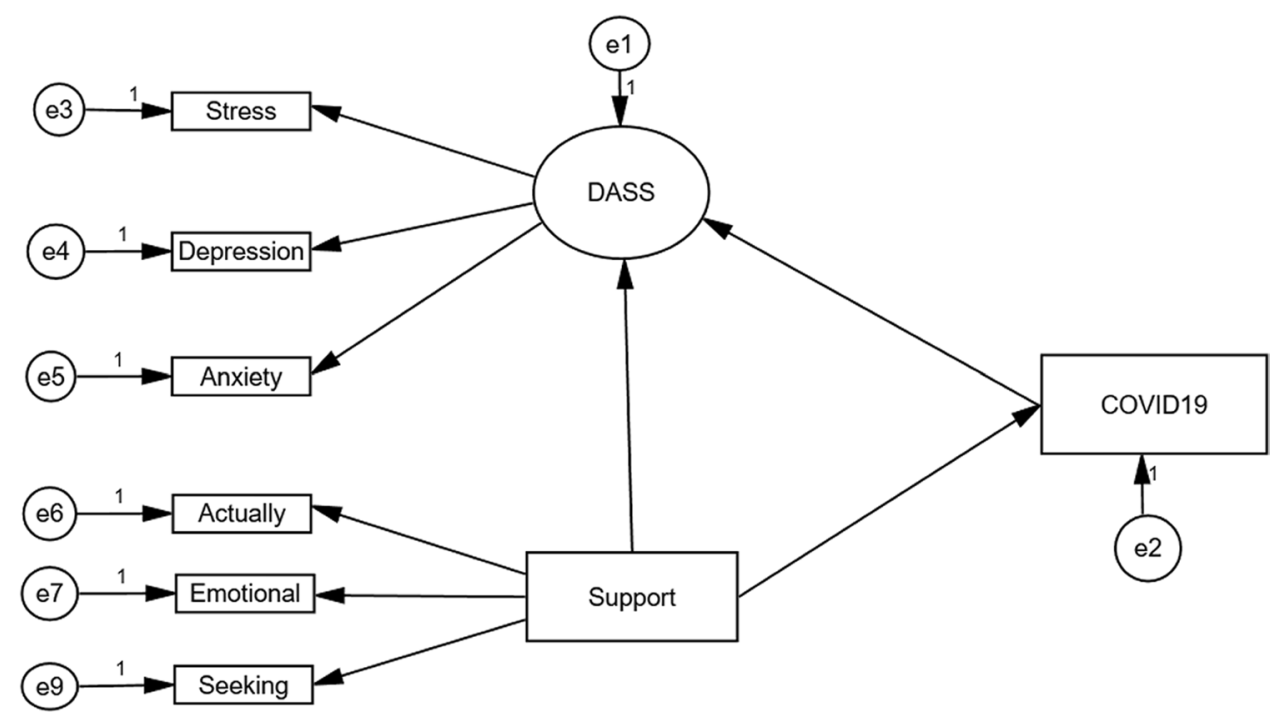

Table 3 Estimates parameters for the structural equation model

\begin{tabular}{lllll}
\hline Model & Parameter & $\beta$ & t value & Hypothesis \\
\hline H1 & Covid-19 DASS21 & .41 & $13.58 * * *$ & Accepted \\
H2 & Social support DASS21 & -.29 & $11.93 * * *$ & Accepted \\
H3 & Social support Covid-19 & -.69 & $13.57 * * *$ & Accepted \\
\hline
\end{tabular}

Standardized solutions are reported. $* p<.05, * * * p<.001$

negatively correlated to anxiety ( $\mathrm{r}=-0.27, p<0.01)$, depression $(\mathrm{r}=-0.20, p<0.01)$, and stress $(\mathrm{r}=-0.21, p<0.01)$.

\section{The SEM}

Results of path analysis in Fig. 2 and the hypothesized model in Fig. 1 showed that fear of COVID-19 as a predictor, social support as a mediating variable, and mental health distress as an outcome variable. In addition, findings concluded that social support mediated the relationship between the two variables, with a good fit for the data $\left(\chi^{2}{ }_{(61)}=241.08\right.$; $p=0.05 ; \mathrm{GFI}=0.94 ; \mathrm{AGFI}=0.89 ; \mathrm{RMSEA}=0.051$; $\mathrm{NFI}=0.95 ; \mathrm{CFI}=0.96)$.
The three main hypotheses of our study were tested with coefficient and $t$ value. Results given in Table 3 showed that all of the $t$ values coefficients are over 1.96, which means that the three main hypotheses should be accepted (Fig. 2).

Concerning the moderating effects (H1), the analysis showed a small negative effect of fear of COVID-19 on psychological distress of $\left(\beta_{\mathrm{X}, \mathrm{Y}}=-0.201 ; p<0.001\right)$. Furthermore, analysis of the path between fear of COVID-19 and social support showed a negative effect $\left(\beta_{\mathrm{M}, \mathrm{Y}}=-0.69\right.$; $p<0.001)$, standardized total direct effect as for $(\mathrm{H} 2)$. Finally, in regards to the full mediation hypothesis (H3), the model presented a standardized total effect of social support on $\left(\beta_{\mathrm{X}, \mathrm{M}}=-0.57 ; p<0.001\right)$. However, this effect was made up of a statistically significant indirect effect (via social support, $\beta_{\mathrm{X}, \mathrm{M}, \mathrm{Y}}=-.286 ; p<0.01$ ) and a statistically significant direct effect $\left(\beta_{\mathrm{X}, \mathrm{Y}, \mathrm{M}}=-0.29 ; p<0.01\right)$. Thus, the relationship between fear of COVID-19 and psychological distress was fully mediated by social support. We also tested the effect of demographic variables: Gender, geographical location, and age in the model, and no significant differences were found in fear of COVID-19, mental health outcomes, and social support due to these variables. 
Fig. 2 Structural equation modeling for fear of Coronavirus (COVID-19) on depression, anxiety and stress, and the mediator role of social support

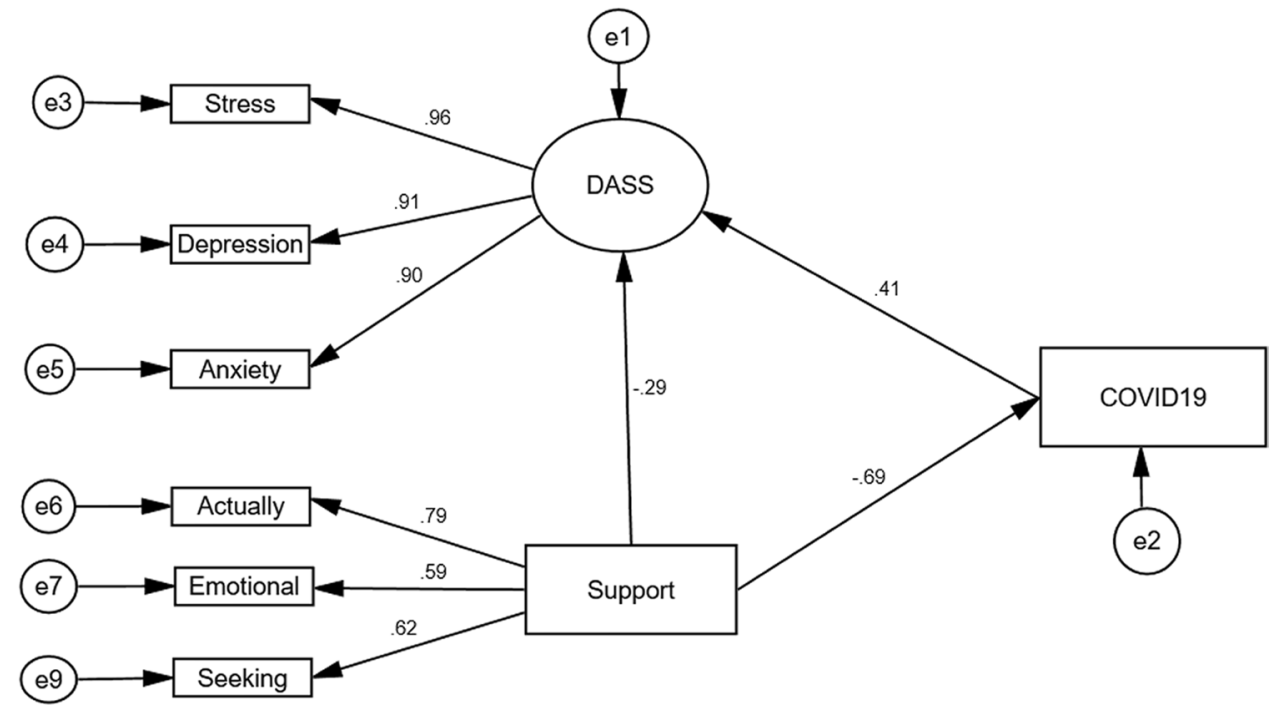

\section{Discussion}

This study investigated the relationship between mental health problems and the fear of COVID-, and whether social support mediated the relationship between the two variables among Palestinians.

\section{Fear of COVID-19 Disease and Mental Health Problems}

Consistent with previous studies (El-Zoghby et al., 2020; Gao et al., 2020; Rajkumar, 2020; Mahamid \& Bdier, 2021a, Satici et al., 2020; Wang et al., 2020), the results of this study presented the fear of COVID-19 as having a negative effect on psychological distresses; consequently that fear of COVID-19 positively associated with mental health problems (depression, anxiety, and stress) among individuals. In addition, individual fears of being infected and death caused rates of depression, anxiety, and stress to increase (Ornell et al., 2020). Moreover, fear of COVID-19 can instigate experiences of stigmatization and social exclusion of confirmed patients, survivors, their families, and others associated with the disease, which can present an increased risk of developing mental health problems (Zhang et al., 2020).

Since individuals are afraid of being infected, they tend to isolate themselves, which negatively impacts their psychological status as they are found to become anxious, stressed, depressed, and exhibit feelings of loneliness (Zandifar \& Badrfam, 2020). In addition, as individuals grew more afraid and began to panic, their work begins to suffer, resulting in a negative impact on their economic status, leading them to get more anxious and stressed (Mamun \& Griffiths, 2020). As many Palestinians work in Israel, they had to stop their work when Israel began to record a high number of infected cases, and as a result, many Palestinians were found to show depressive symptoms and high levels of anxiety (Mahamid $\&$ Bdier, 2021b).

Individuals were anxious, stressed, and depressed when they could not reach their family members and feared that their loved ones might be infected (Mertens et al., 2020). Fear of going out and getting essential supplies such as food and medicine negatively influences an individual's state of mental health (Banerjee, 2020). Rumours and overemphasized information raised levels of fear regarding COVID19 , and as a result, individuals became more anxious and stressed (Zitoun, 2020).

Concerning this study, individuals residing in the occupied territories of Palestine are continually subjugated to high levels of environmental stressors (e.g. militarization, poverty, lack of employment opportunities, cultural pressures, etc.) (Sayegh et al., 2020; Thabet et al., 2013; Mahamid, 2020; Mahamid \& Berte, 2020), and so it is expected that the fear of COVID-19 will impact negatively on the mental health of Palestinians, and make it worse for those with psychological problems.

\section{Social Support and Mental Health Problems}

Social support was found to correlate negatively with stress, depression, and anxiety. Thus this negative correlation was in line with studies indicating that social support was negatively associated with mental health distress (Cabello et al., 2020; Cao et al., 2020; Xiao et al., 2020). Moreover, in another study, cognitive and prosocial coping behaviours contributed to fewer mental health problems associated with the COVID-19 outbreak (Guo et al., 2020). Furthermore, social support among families helped lower depression and anxiety levels among young adults in the U.S. during COVID-19 (Liu et al., 2020). Additionally, Bao et al. (2020) 
defined social support as one strategy that may minimize outbreak-related stress.

One probable explanation for this discovery is that social support was found to improve positive affect and happiness, help individuals cope with sources of stress, provide the needed information and assistance, and make the individuals feel their value, which enhances feelings of self-esteem and self-capability (Agbaria, 2013; Lakey, 2013). Furthermore, social support reduces psychological pressure during epidemics by changing negative thoughts regarding the pandemic and improving help-seeking methods (Cao et al., 2020

Therefore, access to social support may influence the prediction towards effective coping behaviours and facilitate coping strategies, which may alleviate some of the distress that can hinder certain coping efforts. Furthermore, the presence and attainable access of a social network that allows for support may encourage more individuals to seek such support as a coping strategy (Khamis, 2008).

The Tele-Health care service that Palestinian social and psychological specialists provide to the population could help in enacting the mental health of Palestinians (Mahamid \& Veronese, 2020; Veronese et al., 2013), reducing their sense of isolation as well as, establishing the needed psychological help and information (Zhou et al., 2020).

\section{Social Support, Fear of COVID-19 Disease and Mental Health Problems}

Regarding (H3), the correlation between fear of COVID19 and psychological distress was fully mediated by social support. The results of this study are consistent with previous findings, as it was determined that sharing the fear with others will calm the fear and decrease anxiety levels (Kar et al., 2020). Moreover, seeking social support is considered one of the coping strategies that may help overcome the fear related to the outbreak of an epidemic (Chew et al., 2020).

Social support, especially from specialists in the field, decreases fear among individuals by providing them with needed and accurate information, otherwise known as informational support (Koivula et al., 2002). Furthermore, social support plays a crucial role in decreasing fear as it enhances self-worth, social self-confidence, and the feelings that they can control how their lives turn out (Besser \& Priel, 2008).

During the spread of COVID-19, social media platforms (e.g. Facebook, WhatsApp, We Chat, Twitter, and Skype) were used to convey correct information and knowledge, so fear of COVID-19 is likely considered to be lowered (Lin, 2020). In addition, social networks are providing an opportunity to share feelings; if one is feeling afraid, consider reaching out to family, friends, or even a healthcare provider so they can express fears and be better equipped at managing them (Wiederhold, 2020).

\section{Limitations}

The several limitations of this study should give rise to opportunities for future studies. First, it focuses on the fear of COVID-19, mental health problems (depression, anxiety and stress) and social support among adult Palestinians. More studies in different age groups should be conducted in order to generalize the findings. Second, research for the study was based solely on quantitative data collected through online methods via self-reporting questioners. Third, the designs concerning the present study are correlational, and our results are cross-sectional. Thus, longitudinal studies are recommended to investigate the causal relationship between study variables.

\section{Conclusion}

This recent study supports previous research indicating that the fear of COVID-19 has statistically and positively correlated with mental health outcomes (anxiety, depression and anxiety) and that social support was negatively associated with mental health outcomes. Furthermore, the relationship between COVID-19 and fear with psychological distress was fully mediated by social support. These recent findings contribute to the theoretical understanding of how the study variables relate or affect each other and contribute further insights towards practical implications, such as establishing programs that may decrease the fear in crises or emergencies and enhance or protect the mental health of individuals. The results of this study can serve as a guide for the Palestinian Government Ministry of Health and the various non-profit entities serving to coordinate and provide mental health services. The results speak to the need for comprehensive training for professionals, increased access to outpatient mental health services, enhanced clinical supervision and the development of specialized intervention models that can best serve individuals in the unique context of Palestine.

The datasets generated during and analyzed during the current study are available from the corresponding author on reasonable request.

\section{Declarations}

Ethical Approval All procedures performed in this study involving human participants followed the ethical standards of An-Najah University's Research Ethics Board, the American Psychological Association (APA, 2010), and the 1964 Helsinki Declaration.

Informed Consent Informed consent was obtained from all participants. 
Conflict of Interest The authors declare that they have no conflict of interest. No funding was received for this study.

\section{References}

Agbaria, Q. (2013). Depression among Arab students in Israel: The contribution of religiosity, happiness, social support and selfcontrol. Sociology Study, 3(10), 721-738.

Agbaria, Q., \& Bdier, D. (2020). The role of self-control, social support and (positive and negative affects) in reducing test anxiety among Arab teenagers in Israel. Child Indicators Research, 13(3), 1023-1041. https://doi.org/10.1007/s12187-019-09669-9

Agbaria, Q., Mahamid, F., \& Ziya Berte, D. (2017). Social support, self-control, religiousness and engagement in high risk-behaviors among adolescents. The International Journal of Indian Psychology, 4(4), 13-33. https://doi.org/10.25215/0404.142

Ahorsu, D. K., Lin, C. Y., Imani, V., Saffari, M., Griffiths, M. D., \& Pakpour, A. H. (2020). The fear of COVID-19 scale: Development and initial validation. International Journal of Mental Health and Addiction, 1-9. Advance online publication. https://doi.org/10. 1007/s11469-020-00270-8

Ai, T., Yang, Z., Hou, H., Zhan, C., Chen, C., Lv, W., ... \& Xia, L. (2020). Correlation of chest C.T. and RT-PCR testing in coronavirus disease 2019 (COVID-19) in China: A report of 1014 cases. Radiology, 296(2), 200642. https://doi.org/10.1148/radiol. 2020200642

APA. (2010). Ethical principles of psychologists and code of conduct. The American Psychologist, 65, 493. https://doi.org/10.1037/ a0020168

Banerjee, D. (2020). How COVID-19 is overwhelming our mental health. Nature India. Advance online publication. https:// doi.https://doi.org/10.1038/nindia.2020.46

Bao, Y., Sun, Y., Meng, S., Shi, J., \& Lu, L. (2020). 2019-nCoV epidemic: Address mental health care to empower society. The Lancet. Advance online publication. https://doi.org/10.1016/S01406736(20)30309-3

Barbisch, D., Koenig, K. L., \& Shih, F. Y. (2015). Is there a case for quarantine? Perspectives from SARS to Ebola. Disaster Medicine and Public Health Preparedness, 9(5), 547-553. https://doi.org/ $10.1017 / \mathrm{dmp} .2015 .38$

Besser, A., \& Priel, B. (2008). Attachment, depression, and fear of death in older adults: The roles of neediness and perceived availability of social support. Personality and Individual Differences, 44(8), 1711-1725. https://doi.org/10.1016/j.paid.2008.01.016

Brooks, S. K., Webster, R. K., Smith, L. E., Woodland, L., Wessely, S., Greenberg, N., \& Rubin, G. J. (2020). The psychological impact of quarantine and how to reduce it: Rapid review of the evidence. The Lancet, 395(10227), 912-920. https://doi.org/10.1016/S01406736(20)30460-8

Cabello, I. R., Echavez, J. F. M., Serrano-Ripoll, M. J., Fraile-Navarro, D., de Roque, M. A. F., Moreno, G. P., ... \& Goncalves-Bradley, D. (2020). Impact of viral epidemic outbreaks on mental health of healthcare workers: A rapid systematic review. medRxiv. Advance online publication. https://doi.org/10.1101/2020.04.02.20048892

Cao, W., Fang, Z., Hou, G., Han, M., Xu, X., Dong, J., \& Zheng, J. (2020). The psychological impact of the COVID-19 epidemic on college students in China. Psychiatry Research. Advance online publication. https://doi.org/10.1016/j.psychres.2020.112934

Casale, M., Wild, L., Cluver, L., \& Kuo, C. (2014). The relationship between social support and anxiety among caregivers of children in HIV-endemic South Africa. Psychology, Health \& Medicine, 19(4), 490-503. https://doi.org/10.1080/13548506.2013.832780

Cascella, M., Rajnik, M., Cuomo, A., Dulebohn, S. C., \& Di Napoli, R. (2020). Features, evaluation and treatment coronavirus
(COVID-19). In StatPearls [Internet]. StatPearls Publishing. Retrieved from https://www.ncbi.nlm.nih.gov/books/NBK55 4776/. Accessed 31 Jul 2021.

Chew, Q. H., Wei, K. C., Vasoo, S., Chua, H. C., \& Sim, K. (2020). Narrative synthesis of psychological and coping responses towards emerging infectious disease outbreaks in the general population: Practical considerations for the COVID-19 pandemic. Singapore Medical Journal, 61(7), 1-14. https://doi.org/10.11622/smedj. 2020046

Coomes, E. A., Leis, J. A., \& Gold, W. L. (2020). Quarantine. Canadian Medical Association Journal, 192(13), E338-E338. https:// doi.org/10.1503/cmaj.200393

Declaration, H. (1964). Adopted by the 18th World Medical Assembly, Helsinki, Finland, June 1964. Amended by the 29th World Medical Assembly Tokyo, Japan, October, 197

El-Zoghby, S. M., Soltan, E. M., \& Salama, H. M. (2020). Impact of the COVID-19 pandemic on mental health and social support among adult Egyptians. Journal of Community Health, 45(4), 689-695. https://doi.org/10.1007/s10900-020-00853-5

Epstein, J. M., Parker, J., Cummings, D., \& Hammond, R. A. (2008). Coupled contagion dynamics of fear and disease: Mathematical and computational explorations. PLoS ONE, 3(12), e3955. https:// doi.org/10.1371/journal.pone.0003955

Gao, J., Zheng, P., Jia, Y., Chen, H., Mao, Y., Chen, S., ... \& Dai, J. (2020). Mental health problems and social media exposure during COVID-19 outbreak. Plos One, 15(4), e0231924. https://doi.org/ 10.1371/journal.pone.0231924

Gomez, F. (2016). A guide to the depression, anxiety and stress scale (DASS 21). Central and Eastern Sydney Primary Health Networks. Retrieved from https://www.academia.edu/25177167/A_ Guide_to_the_Depression_Anxiety_and_Stress_Scale_DASS_21. Accessed 31 Aug 2021.

Gunzler, D., Chen, T., Wu, P., \& Zhang, H. (2013). Introduction to mediation analysis with structural equation modeling. Shanghai Archives of Psychiatry, 25(6), 390-394. https://doi.org/10.3969/j. issn.1002-0829.2013.06.009

Guo, J., Feng, X. L., Wang, X. H., \& van IJzendoorn, M. H. . (2020). Coping with COVID-19: Exposure to COVID-19 and negative impact on livelihood predict elevated mental health problems in Chinese adults. International Journal of Environmental Research and Public Health, 17(11), 3857. https://doi.org/10.3390/ijerp h17113857

Hair, J. F., Jr., W. C. Black, B. J. Babin, and R. E. Anderson. 2010. Multivariate Data Analysis. Upper Saddle River, New Jersey: Pearson Prentice Hall.

Heymann, D. L., \& Shindo, N. (2020). COVID-19: What is next for public health? The Lancet, 395(10224), 542-545. https://doi.org/ 10.1016/S0140-6736(20)30374-3

Hossain, M. M., Sultana, A., \& Purohit, N. (2020). Mental health outcomes of quarantine and isolation for infection prevention: A systematic umbrella review of the global evidence. Advance Online Publication. https://doi.org/10.2139/ssrn.3561265

Huang, J. Z., Han, M. F., Luo, T. D., Ren, A. K., \& Zhou, X. P. (2020). Mental health survey of 230 medical staff in a tertiary infectious disease hospital for COVID-19. Zhonghua lao dong wei sheng zhi ye bing za zhi= Zhonghua laodong weisheng zhiyebing zazhi= Chinese Journal of Industrial Hygiene and Occupational Diseases, 38(3), 192- 195. https://doi.org/10.3760/cma.j.cn12109420200219-00063

Huremović, D. (Ed.). (2019). Psychiatry of pandemics: A mental health response to infection outbreak. Springer.

Ivchenko, A., Jachimowicz, J., King, G., Kraft-Todd, G., Ledda, A., MacLennan, M., ... \& Slepoi, F. R. (2020). Evaluating COVID-19 public health messaging in Italy: Self-reported compliance and growing mental health concerns. MedRxiv. Advance online publication. https://doi.org/10.1101/2020.03.27.20042820 
Jung, S. J., \& Jun, J. Y. (2020). Mental health and psychological intervention amid COVID-19 outbreak: Perspectives from South Korea. Yonsei Medical Journal, 61(4), 271-272. https://doi.org/ 10.3349/ymj.2020.61.4.271

Kar, S. K., Arafat, S. Y., Kabir, R., Sharma, P., \& Saxena, S. K. (2020). Coping with mental health challenges during COVID-19. In Coronavirus Disease 2019 (COVID-19) (pp. 199-213). Springer, Singapore. https://doi.org/10.1007/978-981-15-4814-7_16

Khamis, V. (2008). Post-traumatic stress and psychiatric disorders in Palestinian adolescents following intifada-related injuries. Social Science \& Medicine, 67(8), 1199-1207. https://doi.org/10.1016/j. socscimed.2008.06.013

Koivula, M., Paunonen-Ilmonen, M., Tarkka, M. T., Tarkka, M., \& Laippala, P. (2002). Social support and its relation to fear and anxiety in patients awaiting coronary artery bypass grafting. Journal of Clinical Nursing, 11(5), 622-633. https://doi.org/10.1046/j. 1365-2702.2002.00653.x

Lakey, B. (2013). Perceived social support and happiness: The role of personality and relational processes. In Oxford Handbook of Happiness.

Lee, S. M., Kang, W. S., Cho, A. R., Kim, T., \& Park, J. K. (2018). Psychological impact of the 2015 MERS outbreak on hospital workers and quarantined hemodialysis patients. Comprehensive Psychiatry, 87, 123-127. https://doi.org/10.1016/j.comppsych. 2018.10 .003

Lin, C. Y. (2020). Social reaction toward the 2019 novel coronavirus (COVID-19). Social Health and Behavior, 3(1), 1-2. https://doi. org/10.4103/SHB.SHB_11_20

Liu, C. H., Zhang, E., Wong, G. T. F., \& Hyun, S. (2020). Factors associated with depression, anxiety, and PTSD symptomatology during the COVID-19 pandemic: Clinical implications for U.S. young adult mental health. Psychiatry Research, 290, 113172. https://doi.org/10.1016/j.psychres.2020.113172

Mahamid, F. A., \& Bdier, D. (2021a). The association between positive religious coping, perceived stress, and depressive symptoms during the spread of coronavirus (COVID-19) among a sample of adults in Palestine: Across sectional study. Journal of Religion and Health, 60, 34-49. https://doi.org/10.1007/s10943-020-01121-5

Mahamid, F. A., \& Bdier, D. (2021b). Fear of COVID-19 and Mental Health Outcomes among Psychosocial Service Providers in Palestine: The Mediating Role of Well-Being. Journal of Concurrent Disorders, 3(1), 45-60.

Mahamid, F. A. (2020). Collective trauma, quality of life and resilience in narratives of third generation palestinian refugee children. Child Indicators Research, 13, 2181-2204. https://doi.org/ 10.1007/s12187-020-09739-3

Mahamid, F., \& Veronese, G. (2020). Psychosocial interventions for third-generation palestinian refugee children: Current challenges and hope for the future. International Journal of Mental Health and Addiction. Advance online publication. https://doi.org/10. 1007/s11469-020-00300-5.

Mahamid, F., \& Berte, D. Z. (2020). Happiness, Sadness, and Hope for the Future in Narratives of Palestinian Refugee Children. International Journal of Mental Health and Addiction, 18, 1638-1651. https://doi.org/10.1007/s11469-020-00303-2

Mahamid, F.A., Veronese, G., Bdier, D., \& Pancake, R. (2021). Psychometric properties of the COVID stress scales (CSS) within Arabic language in a Palestinian context. Current Psychology. Advance online publication. https://doi.org/10.1007/s12144-021-01794-5

Mamun, M. A., \& Griffiths, M. D. (2020). First COVID-19 suicide case in Bangladesh due to fear of COVID-19 and xenophobia: Possible suicide prevention strategies. Asian Journal of Psychiatry, 51, 102073. https://doi.org/10.1016/j.ajp.2020.102073

Matsumoto, S., Yamaoka, K., Takahashi, K., Tanuma, J., Mizushima, D., Do, C. D., ... \& Oka, S. (2017). Social support as a key protective factor against depression in HIV-infected patients: Report from large HIV clinics in Hanoi, Vietnam. Scientific Reports, 7(1), $1-12$.

Mertens, G., Gerritsen, L., Salemink, E., \& Engelhard, I. (2020). Fear of the coronavirus (COVID-19): Predictors in an online study conducted in March 2020. Journal of Anxiety Disorders, 74, 102258. https://doi.org/10.1016/j.janxdis.2020.102258

Ornell, F., Schuch, J. B., Sordi, A. O., \& Kessler, F. H. P. (2020). "Pandemic fear" and COVID-19: Mental health burden and strategies. Brazilian Journal of Psychiatry, 42(3), 232-235. https://doi.org/ 10.1590/1516-4446-2020-0008

Rajkumar, R. P. (2020). COVID-19 and mental health: A review of the existing literature. Asian Journal of Psychiatry, 52, 102066. https://doi.org/10.1016/j.ajp.2020.102066

Ronen, T., Hamama, L., Rosenbaum, M., \& Mishely-Yarlap, A. (2016). Subjective well-being in adolescence: The role of selfcontrol, social support, age, gender, and familial crisis. Journal of Happiness Studies, 17(1), 81-104. https://doi.org/10.1007/ s10902-014-9585-5

Rubin, G. J., \& Wessely, S. (2020). The psychological effects of quarantining a city. British Medical Journal, 368, m313. https://doi. org/10.1136/bmj.m313

Satici, B., Gocet-Tekin, E., Deniz, M. E., \& Satici, S. A. (2020). Adaptation of the Fear of COVID-19 Scale: Its association with psychological distress and life satisfaction in Turkey. International Journal of Mental Health and Addiction, 1-9. Advance Online Publication. https://doi.org/10.1007/s11469-020-00294-0

Sayegh, A., Hussein, N., \& Bdier, D. (2020). Internet addiction and achievement motivation among university students. Journal of Concurrent Disorders. Advance Online Publication. Retrieved from https://concurrentdisorders.ca/2020/11/22/inter net-addiction-and-achievement-motivation-among-universitystudents/. Accessed 15 Aug 2021

Schwarzer, R., \& Schulz, U. (2013). Berlin social support scales (BSSS). Measurement Instrument Database for the Social Science. https://doi.org/10.13072/midss.490

Shigemura, J., Ursano, R. J., Morganstein, J. C., Kurosawa, M., \& Benedek, D. M. (2020). Public responses to the novel 2019 coronavirus (2019-nCoV) in Japan: Mental health consequences and target populations. Psychiatry and Clinical Neurosciences, 74(4), 281-282. https://doi.org/10.1111/pcn.12988

Shultz, J. M., Cooper, J. L., Baingana, F., Oquendo, M. A., Espinel, Z., Althouse, B. M., ... \& Mazurik, L. (2016). The role of fear-related behaviors in the 2013-2016 West Africa Ebola virus disease outbreak. Current Psychiatry Reports, 18(11), 104. https://doi.org/ 10.1007/s11920-016-0741-y

Simard, S., Thewes, B., Humphris, G., Dixon, M., Hayden, C., Mireskandari, S., \& Ozakinci, G. (2013). Fear of cancer recurrence in adult cancer survivors: A systematic review of quantitative studies. Journal of Cancer Survivorship, 7(3), 300-322. https://doi. org/10.1007/s11764-013-0272-z

Steptoe, A., Shankar, A., Demakakos, P., \& Wardle, J. (2013). Social isolation, loneliness, and all-cause mortality in older men and women. Proceedings of the National Academy of Sciences, 110(15), 5797-5801. https://doi.org/10.1073/pnas.1219686110

Thabet, A. A., Tawahina, A. A., Sarraj, E. E., \& Vostanis, P. (2013). Death anxiety, PTSD, trauma, grief, and mental health of Palestinians victims of war on Gaza. Health Care: Current Reviews, 112, 1-8. https://doi.org/10.4172/hccr.1000112

Veronese, G., Fiore, F., Castiglioni, M., el Kawaja, H., \& Said, M. (2013). Can sense of coherence moderate traumatic reactions? A cross-sectional study of Palestinian helpers operating in war contexts. British Journal of Social Work, 43(4), 651-666. https:// doi.org/10.1093/bjsw/bcs005

Veronese, G., Mahamid, F., Bdier, D., \& Pancake, R. (2021). Stress of COVID-19 and mental health outcomes in Palestine: The 
mediating role of well-being and resilience. Advance online publication. https://doi.org/10.5114/hpr.2021.104490

Wang, C., Pan, R., Wan, X., Tan, Y., Xu, L., Ho, C. S., \& Ho, R. C. (2020). Immediate psychological responses and associated factors during the initial stage of the 2019 coronavirus disease (COVID19) epidemic among the general population in china. International Journal of Environmental Research and Public Health, 17(5), 1729. https://doi.org/10.3390/ijerph17051729

Wiederhold, B. K. (2020). Social media use during social distancing. Cyberpsychology, Behavior, and Social Networking, 23(5), 275276. https://doi.org/10.1089/cyber.2020.29181.bkw

World Health Organization. (2021a). Weekly epidemiological update on COVID-19 - 20 July. Retrieved July 20, 2021 from https://www.who.int/publications/m/item/weekly-epidemiolo gical-update-on-covid-19---20-july-2021

World Health Organization. (2021b). Occupied Palestinian territory, including east Jerusalem. Retrieved July 23, 2021, from https:// covid19. who.int/region/emro/country/ps

Woon, L.S.-C., Sidi, H., Nik Jaafar NR, Leong Bin Abdullah MFI. (2020) Mental Health Status of University Healthcare Workers during the COVID-19 Pandemic: A Post-Movement Lockdown Assessment. International Journal of Environmental Research and Public Health, 17(24):9155. https://doi.org/10.3390/ijerp h17249155

Woon, L. S. C., Abdullah, L. B., \& M. F. I., Sidi, H., Mansor, N. S., \& Nik Jaafar, N. R. . (2021). Depression, anxiety, and the COVID-19 pandemic: Severity of symptoms and associated factors among university students after the end of the movement lockdown. PLoS ONE, 16(5), e0252481. https://doi.org/10.1371/ journal.pone.0252481

Wu, Z., \& McGoogan, J. M. (2020). Characteristics of and important lessons from the coronavirus disease 2019 (COVID-19) outbreak in China: Summary of a report of 72314 cases from the Chinese
Center for Disease Control and Prevention. Journal of the American Medical Association, 323(13), 1239-1242. https://doi.org/10. 1001/jama.2020.2648

Xiang, Y. T., Yang, Y., Li, W., Zhang, L., Zhang, Q., Cheung, T., \& Ng, C. H. (2020). Timely mental health care for the 2019 novel coronavirus outbreak is urgently needed. The Lancet Psychiatry, 7(3), 228-229. https://doi.org/10.1016/S2215-0366(20)30046-8

Xiao, H., Zhang, Y., Kong, D., Li, S., \& Yang, N. (2020). The effects of social support on sleep quality of medical staff treating patients with coronavirus disease 2019 (COVID-19) in January and February 2020 in China. Medical Science Monitor: International Medical Journal of Experimental and Clinical Research, 26, e923549. https://doi.org/10.12659/MSM.923549

Zandifar, A., \& Badrfam, R. (2020). Iranian mental health during the COVID-19 epidemic. Asian Journal of Psychiatry, 51, 101990. https://doi.org/10.1016/j.ajp.2020.101990

Zhang, J., Wu, W., Zhao, X., \& Zhang, W. (2020). Recommended psychological crisis intervention response to the 2019 novel coronavirus pneumonia outbreak in China: A model of West China Hospital. Precision Clinical Medicine, 3(1), 3-8. https://doi.org/ 10.1093/pcmedi/pbaa006

Zhou, X., Snoswell, C. L., Harding, L. E., Bambling, M., Edirippulige, S., Bai, X., \& Smith, A. C. (2020). The role of telehealth in reducing the mental health burden from COVID-19. Telemedicine and e-Health, 26(4), 377-379. https://doi.org/10.1089/tmj.2020.0068

Zitoun, O. A. (2020). COVID-19 pandemic: Other perspective. Saudi Arabia. International

Publisher's note Springer Nature remains neutral with regard to jurisdictional claims in published maps and institutional affiliations. 